\title{
O livro e a sua mediação na infância ${ }^{1}$
}

\author{
THE book and it's mediation in childhood \\ Marilia Forgearini Nunes \\ Júlia Soares Martini \\ Universidade Federal do Rio Grande do Sul - UFRGS - Porto Alegre - Rio Grande do Sul - Brasil
}

Resumo: O livro na Educação Infantil é um objeto a ser descoberto pelas crianças. Nosso objetivo nesse trabalho foi refletir sobre a mediação do livro como objeto de sentido com características próprias a serem conhecidas pelo leitor na Educação Infantil. Para isso, analisamos um capítulo do livro Alice no jardim de infância (CARROL, [1890]2013) (uma versão recontada pelo próprio autor, adaptada para crianças de zero a cinco anos) para observar como o narrador amplia as possibilidades interativas com a narrativa e com o livro. Essa análise possibilitou percebermos como a voz narrativa associada à organização gráfica do livro podem ser importantes recursos de mediação para aproximar o leitor da Educação Infantil e o livro, contagiando esse leitor a interagir com o suporte do texto, promovendo o seu letramento.

Palavras-chave: Livro infantil, mediação, interação.

Abstract:: The book in early childhood education is an object to be discovered by children. Our purpose in this paper was to reflect about the mediation of the book as an object of meaning with singular characteristics to be known by the reader in early childhood education. To this end, we analysed a chapter of the book Alice in Wonderland (Alice no jardim de infância (CARROL, [1890]2013) in Portuguese) (a version retold by the author himself, adapted for children from zero to five years) to observe how the narrator amplifies the possibilities of interaction with the narrative and with the book. This analysis made us realize that the narrative voice, associated with the graphic organization of the book can be important resources of mediation to bring closer the reader in early childhood and the book, affecting this reader into interacting with the text support, promoting his or her's literacy.

Keywords: Children's book, mediation, interaction.

\footnotetext{
${ }^{1}$ Trabalho realizado como parte da pesquisa "Mediação cultural e produção de sentido: diferentes objetos e espaços.
} 


\section{Introdução}

O surgimento da possibilidade de abandonar as edições manuscritas e imprimir livros possibilitou 0 acesso ao livro como objeto que pode ser possuído, guardado, manuseado e lido individualmente. A leitura assume, a partir do século XVIII, um novo modo de existir em sociedade, estando presente em todos os momentos, podendo ser feita de modo solitário, sobrepondo-se à cultura do manuscrito e da oralidade que existia na Europa até então (BELO, 2008).

Há, no entanto, um contexto de leitura e um modo de ler no qual essa solidão não se modificou nem se tornou característica, a escola. As leituras que acontecem no ambiente da Educação Infantil permanecem com o caráter coletivo e solidário que caracterizava 0 ato de ler antes da prensa de Gutenberg e até mesmo no princípio do surgimento dessa invenção. Permanece na sala de aula da Educação Infantil a cultura da oralidade, da voz do outro que lê e dá vida ao texto escrito.

O livro é um objeto contemporaneamente presente nas salas de aula da Educação Infantil. Essa presença é decorrente da compreensão de que as crianças estão inseridas na cultura escrita em seu cotidiano e precisam aprender a agir de modo significativo com essa cultura e seus objetos. Nesse contexto, a leitura do livro literário infantil, objeto verbo-visual, torna-se uma experiência necessária para promover a inserção das crianças nas práticas de leitura que precisam ser significativas e conhecedoras não somente do livro em seus diferentes formatos, mas também das linguagens que constituem seu texto o sistema alfabético.

Para Hunt (2010), não há como fugir, ao menos nesse momento híbrido entre narrativas lineares e hipertextuais, de lidar tanto com o livro quanto com os textos móveis a partir de seus diferentes dispositivos (computadores, tablets ou leitores de livros digital, celulares). Associada a esse hibridismo de mídias, o livro, como objeto exemplar da impressão escrita e visual, ainda precisa ser mediado para que a leitura feita a partir dele seja produtora de sentido. O presente trabalho investiga a mediação da leitura desse objeto presente em nossa sociedade há alguns séculos, mas que não foi suplantado, ainda pode ser atrativo mesmo diante das mudanças tecnológicas que não pararam em Gutenberg e possibilitar novos modos de ler e interação importantes na formação leitora de crianças.

Refletiremos sobre como um livro, a partir da voz do narrador da história, pode auxiliar o mediador oferecendo ao leitor outros modos de explorar esse objeto. O livro, a partir do qual nossa argumentação será delineada, é Alice no Jardim de Infância (CARROLL, [1890] 2013), uma releitura do clássico, feita pelo próprio autor, Lewis Carroll, como explica o texto da quarta capa do livro: "Concebido e escrito entre 1889 e 1890, o livro Alice no jardim de infância é uma obra de Lewis Caroll que se propõe a recontar, para crianças de "zero a cinco anos" as aventuras da menina Alice no País das Maravilhas.". Considerando a extensão desse texto, nos deteremos no primeiro capítulo dessa obra: 1. O Coelho Branco (CARROLL, [1890] 2013, p.10-13).

A voz narrativa, percebida ao longo do texto, permite ao mediador e ao leitor renovarem o ato de ler com uma abertura à interatividade próxima do que se entende que seja a relação com a leitura a partir dos dispositivos eletrônicos, que surgem anunciando o fim do livro de papel. Nosso objetivo, ao voltar a atenção para essa voz narrativa é refletir sobre a mediação do livro como objeto de sentido com características próprias a serem conhecidas pelo leitor em formação na Educação Infantil, independente de estarmos vivendo, talvez, o desaparecimento do livro como suporte de leitura ${ }^{2}$. Para isso, faremos a análise do capítulo 1 do livro Alice no jardim de infância (CARROLL, [1890] 2013, p.10-13), identificando que pistas o narrador deixa ao mediador para que possa oportunizar a leitura do livro de modo mais interativo que o simples abrir do livro.

\footnotetext{
2 A discussão sobre a relação entre tecnologia e leitura, envolvendo inclusive o possível desaparecimento do livro como objeto a partir dessa relação, pode ser encontrada em publicações relevantes já no final dos anos 1990, como por exemplo: $A$ aventura do livro: do leitor ao navegador (CHARTIER, 1998), ou já no início dos anos 2000, com o livro Fim do livro, fim dos leitores? (ZILBERMAN, 2001).
} 


\section{0 que é um livro?}

Para começarmos a pensar sobre o tempo presente, é preciso refletir sobre o passado. À vista disso, acreditamos ser relevante iniciar falando sobre a história do livro e o que ele veio a se tornar para a sociedade, levando especialmente em consideração o conceito de livro voltado para o público da infância, que é o nosso foco de análise.

Durante a Antiguidade e a Idade Média, a cultura dominante era a do manuscrito e da oralidade, ou seja, a distribuição de conhecimento e informação era feita pela leitura coletiva (BELO, 2008, p. 24). Um novo modo de acessar o conhecimento surge com a cultura impressa a partir do século XV, aumentando a possibilidade de acesso à leitura, por permitir maior circulação de livros e, com isso, trazendo o comportamento da leitura individual e em silêncio que realizamos até hoje.

Temos conhecimento sobre o que é um livro e utilizamos essa palavra como uma metáfora para designar qualquer base de texto (BELO, 2008), mas o que seria o Livro Infantil? De acordo com Guto Lins (2003), o Livro Infantil é "um livro que, pela temática, pelo uso de imagem, pelas cores, pelo formato, [é indicado] [...] principalmente para crianças.", mais precisamente, "o livro infantil mantém o papel de estimular a criança a ser criança, a criar." (LINS, 2003, p. 31). Ele tem o papel de ser um mediador para o desenvolvimento da criatividade na infância, dentre outras possibilidades de interação comunicativa, social e de desenvolvimento cognitivo também relacionados ao acesso ao livro infantil.

Pensamos no livro como um objeto de interação, que será lido e relido de diferentes maneiras e produzirá diferentes sentidos a partir de cada leitor. Temos o livro como uma ferramenta literária com o principal objetivo, o de contar histórias (LINS, 2003). Com os recursos do projeto gráfico, da imagem, cada história possui uma grande variedade de maneiras de ser contada.

O livro Alice no Jardim de Infância (CARROLL, [1890] 2013) demonstra como tais recursos associados a um texto simplificado pelo autor podem constituir uma história recontada que pode ser lida como uma nova. Guto Lins em seu livro "Livro infantil?: projeto gráfico, metodologia, subjetividade" (2003), discute a possibilidade de se ter a mesma história contada de diferentes maneiras a partir da imagem, apresenta exemplos com a personagem de Lewis Carroll representada de diferentes maneiras por diferentes ilustradores (Willy Pogany, Barry Moser, D.R. Sexton, Dusan Kalai), incluindo a mais clássica delas, a de Tenniel que está presente no livro que analisamos neste trabalho (FIGURA 1). A maneira como cada uma dessas "Alices" é mostrada modifica a percepção do leitor sobre a leitura, muda os significados produzidos e a relação com o livro. Não somente as imagens, mas todo o projeto gráficoeditorial são produtores de sentido e precisam ser considerados na mediação da leitura.

Figura 1

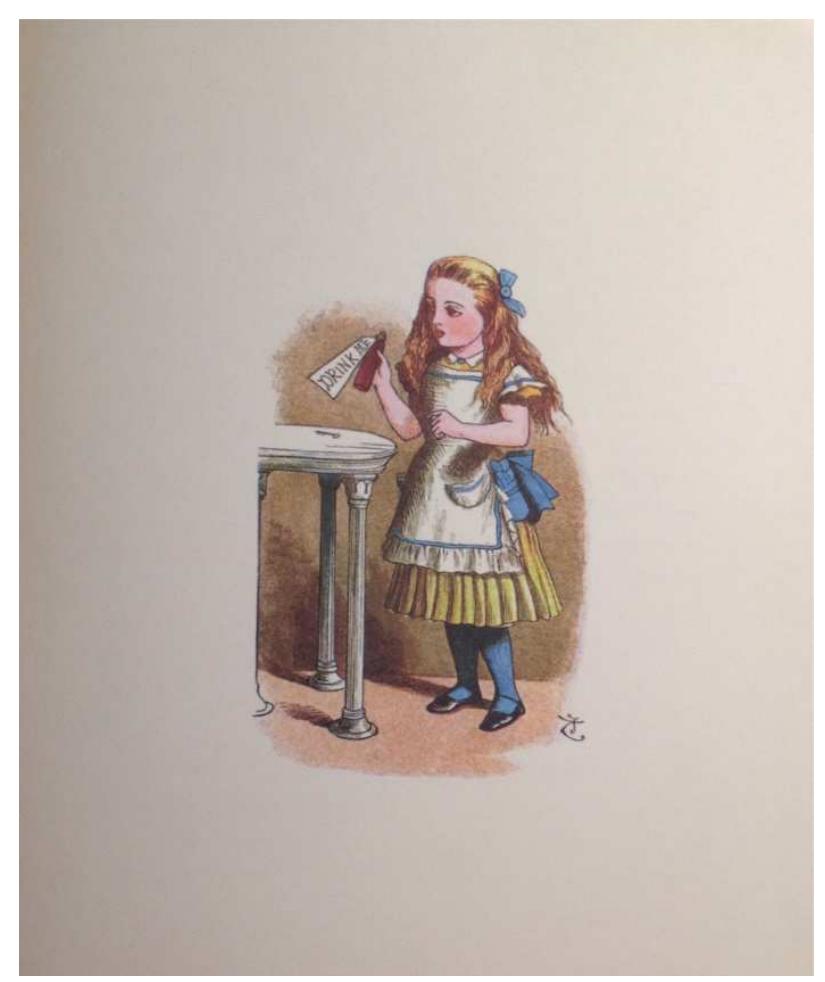

Fonte: CARROLL, [1890] (2013), p.15.

Peter Hunt (2010, p.78), ao tentar definir o que é literatura infantil, fala-nos de modos de ler, mencionando "três situações de leitura [que] precisam ser distinguidas" e que para nossas reflexões precisam ser consideradas: "o adulto que lê um livro destinado a adultos, o adulto que lê um livro destinado a crianças e a criança que lê um livro destinado a crianças". Ao falar sobre a criança que lê 
um livro pensado para ela, o autor caracteriza essa ação como um render-se ao livro, no caso do adulto isto significa aceitar o papel implícito de leitor infantil que o texto prevê e deixa transparecer. Essa entrega ao texto, ou a uma experiência de leitura gratificante como Peter Hunt (2010, p.81) define, que é contagiada pelo modo de constituição verbal, visual, gráfica do livro, proporciona maior abertura ao sentido, não um sentido racionalizado, mas ao sentido em ato, proveniente do contágio causado pela própria leitura.

A partir dessa perspectiva interativa, a leitura torna-se experiência que, para ser compreendida, necessita que voltemos nossa atenção para compreender o livro, como objeto que pode buscar intencionalmente o interesse do leitor e o mediador pode aproveitar dessa intencionalidade. Dessa maneira, mediar o relacionamento da criança com o livro é saber explorar tanto o livro quanto a capacidade da criança de produzir sentidos. Ler não se resume a decodificar, nem a compreender as ideias do autor, a leitura assume um fazer produtor de sentidos que se constroem a partir do leitor, do texto e da interação leitora.

A leitura é, pois, uma atividade interativa altamente complexa de produção de sentidos, que se realiza evidentemente com base nos elementos linguísticos presentes na superfície textual e na sua forma de organização, mas requer um vasto conjunto de saberes no interior do evento comunicativo (KOCH, 2006, p.11).

Estes saberes, inerentes ao evento comunicativo, como inúmeros outros fatores, acabam por influenciar e transformar a nossa leitura em algo singular. Cada leitor se encontra em um meio diferente, com um diferente grupo que reproduz diferentes atitudes e possuem diferentes valores. Por isso, é impossível afirmar que existe somente um único sentido para o texto $(\mathrm{KOCH}, 2006$, p. 19). Levando em consideração a semiótica, que é a teoria da produção de sentido que toma o texto como objeto de significação, procurando compreender como os elementos que o constituem produzem sentido (MATTE, 2009) e também como esse sentido é apreendido na dimensão interacional dos processos (LANDOWSKI, 2014b), reforçamos a nossa compreensão sobre o que é ler como ato que possibilita a produção de inúmeros sentidos resultados de um mesmo objeto textual, o texto literário a partir de diferentes olhares leitores.

\section{Mediar a leitura na Educação Infantil: muito mais do que dar voz ao texto escrito}

A leitura possui caráter solidário e coletivo na Educação Infantil. Essa etapa da Educação Básica é, em geral e tradicionalmente, o primeiro local de convivência social da criança fora do seu núcleo familiar, oportunizando o convívio com diferentes personalidades e situações comunicativas. A hora da leitura literária em roda, por exemplo, uma dessas situações de comunicação predominantemente escolar, é muito comum na Educação Infantil.

A experiência da leitura mediada de um livro de literatura infantil em roda com outros colegas é momento que permite o exercício da coletividade, de compreender que o livro lido é o mesmo, porém os sentidos produzidos a partir dessa leitura podem ser diversos. Conversas decorrentes da mediação da leitura literária podem oportunizar, como nos dizem Maria Amélia Dalvi, Marta Quadros e Kenia Silva (2016, p.32-33) "imprescindível contribuição" ao desenvolvimento de diferentes necessidades infantis relacionadas a questões cognitivas, psicológicas e sociológicas tais como:

domínio da linguagem e aprimoramento dos recursos linguísticos; de interação com sujeitos de comunidades cada vez mais amplas e diferentes; de aprendizado permanentemente; de busca por informações e respostas no roldão de conhecimentos e recursos acumulados pela humanidade; de mergulho na fantasia; de exploração e complexificação do cotidiano; de (sentimento de) pertença ou pertencimento histórico, social e cultural; de protagonismo, por meio a ação-intervenção transformadora

A existência da leitura literária por prazer é, portanto, ação importante no contexto da Educação Infantil, precisando ser, no entanto, mediada pelo educador a partir da perspectiva da leitura como ação interativa que pretende a produção de sentido. Mediar 
a leitura na Educação Infantil não se resume a dar voz ao texto escrito, diante do livro a criança precisa se sentir atraída, intrigada pelo que está sendo mostrado a ela. A maneira como a leitura literária é abordada no cotidiano influencia no modo como ela será recebida. Além disso, lembrando que o contato com o livro literário é parte do processo de formação de futuros leitores, o modo como os adultos interagem com o livro é percebido pelas crianças, assim como tudo mais e, portanto, precisa ser feito de maneira intencional, utilizando estratégias de motivação adequadas ao leitor da Educação Infantil.

Esse leitor, como já dissemos possui necessidades específicas, e a mediação da leitura planejada para ele, um ainda não leitor da palavra mas leitor do mundo, precisa considerar tais necessidades, aquelas ainda em desenvolvimento, bem como habilidades já adquiridas. $\mathrm{O}$ ato de mediar, portanto é pensado a partir da compreensão do desenvolvimento decorrente da interação social, um entendimento que se baseia nas ideias de Vigotski, ao colocar a criança como construtora de significados decorrentes das conexões feitas entre seus conhecimentos prévios e as novas experiências vividas, interação que resultará em aprendizagem a partir daquilo que lhe for desafiador e significativo (VIGOTSKI, 1998). Quem possui a função de intermediar esses conhecimentos de maneira significativa, desafiadora ou atrativa é o professormediador que auxiliará na provocação de conflitos essenciais para a aprendizagem. Na experiência de mediação planejada pelo mediador, cria-se a partir do objeto do conhecimento um "espaço" entre o que a criança já é capaz de fazer sozinha e fazeres que ainda não realiza de modo independente, necessitando ainda de auxílio de alguém mais experiente. É nesse 'quase' que o mediador realiza o seu trabalho.

No caso da experiência de leitura mediada pensada para crianças da Educação Infantil, a leitura do verbal está no campo de conhecimentos que a criança ainda não é capaz de fazer sozinha, porém a leitura da imagem pode ser feita de modo independente, necessitando, talvez, de auxílio para que seja lida como texto produtor de sentido que enriquece o verbal. A mediação da leitura é o fazer que busca, por meio de estratégias, "transformar o estado de funcionamento cognitivo" (GOMES, 2002, p. 77) para que o indivíduo reaja de modo diferente diante da experiência vivida, ultrapasse o não ler ou ler apenas com apoio e alcance a leitura independente, um processo que obviamente não acontece apenas por meio de uma leitura, mas sim a partir das diferentes experiências de leitura mediada proporcionadas ao leitor infantil.

Segundo pesquisa realizada anteriormente com crianças de 4 e 5 anos, o engajamento do leitor mediador na leitura é fundamental para auxiliar as crianças a experimentarem a leitura. Para isso, o mediador precisa estar atento a alguns princípios (NUNES, 2007): "a mediação serve para indicar caminhos e não para dar respostas prontas" (p.108) e não ter "medo dos silêncios da criança, buscando fazer questionamentos até que a criança acabe por construir alguma ideia a partir do diálogo estabelecido." (p.109).

Além disso, o fazer mediador passa, imprescindivelmente, pelo conhecimento do livro que será mediado. Esse olhar leitor atento do mediador possibilitará que sejam descobertos possíveis efeitos de sentido que auxiliarão a formular questionamentos para provocar o diálogo sobre o que foi lido. Conhecer o texto e como ele produz sentido, tanto a partir dos recursos verbais quanto dos recursos visuais enriquece a mediação, amplia as possibilidades de interação.

\section{A voz narrativa como elemento mediador}

Analisar o capítulo selecionado do livro de Lewis Carroll é o que passamos a fazer a partir daqui. Esse movimento é necessário e importante para que - mediador planeje a sua experiência de leitura mediada conhecendo algumas das possibilidades de interação que a leitura oferece, por certo que outras surgirão considerando que a interação com o texto é abertura aos sentidos a partir da leitura. 
O capítulo analisado é o primeiro do livro, "O Coelho Branco", que inicia a narrativa, dando nome a sua personagem principal e situando o primeiro fato surpreendente que acontece com ela após ter um sonho. A primeira frase assume um tom convidativo ao leitor: "Era uma vez uma garotinha chamada Alice que teve um sonho muito curioso. Você gostaria de saber o que foi que ela sonhou?" (CARROLL, [1890]2013, p. 10).

Esse convite faz com que nossa atenção se volte para a voz do narrador. Essa voz assume uma função não apenas como elemento da estrutura narrativa, mas como um auxiliar para realizar a mediação da leitura desse texto. Passamos a compreender que a voz do narrador é:

a manifestação da sua presença observável ao nível do enunciado narrativo, para além da sua primordial função de mediador da história contada; trata-se [...] de atentar nas chamadas intrusões do narrador [grifo dos autores], enquanto afloramentos mais ou menos impressivos de uma subjetividade (sic)" (REIS e LOPES, 1990, p. 402).

Trata-se de um narrador que não vive a história, porém não esconde seus registros subjetivos para auxiliar o leitor a saber mais sobre os personagens, suas ações e como olhar as imagens, a que está presente no capítulo 1 (o coelho olhando para o relógio) e outras imagens que virão nos próximos capítulos. Diferentes modos de interagir com o leitor são estabelecidos por essa voz narrativa:

- Descrever a imagem que se apresenta na página seguinte, considerando o projeto editorial do livro, (FIGURA 2);

\section{Figura 2}

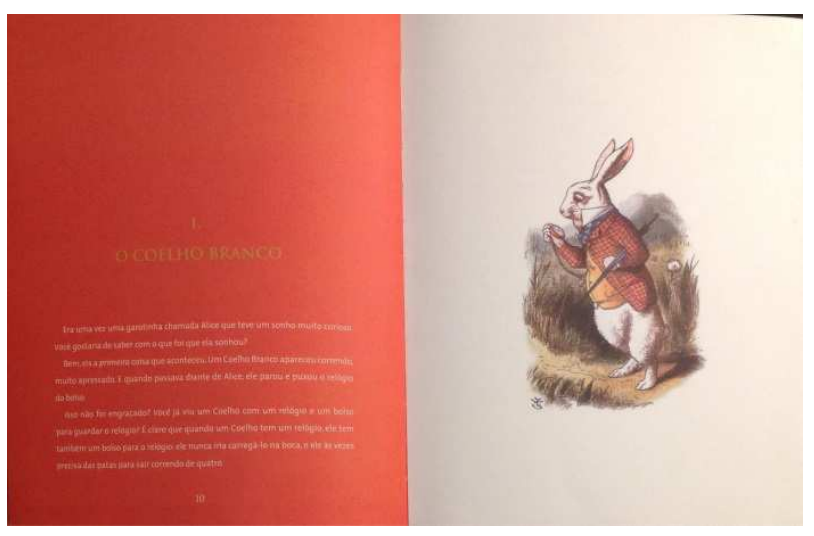

Fonte: CARROLL, [1890]2013, p.10-11.
- Motivar para seguir a leitura e conhecer outros personagens: "Você logo verá um retrato da Duquesa sentada na sua cozinha" (CARROLL, [1890], 2013, p. 12);

- Provocar o leitor a interagir com o livro para além do passar as páginas: "Você não percebe o quanto ele está trêmulo? Basta mexer o livro para cima e para baixo que você imediatamente o verá tremer." (CARROLL, [1890], 2013, p. 12);

É um narrador que assume seu papel de mediador para o leitor que não sabe ler o texto verbal, apenas ouve a sua leitura, mas que poderá se contagiar e procurar ler as imagens. Por meio de sua voz, estabelece um movimento mediador, propondo que a pessoa que estiver lendo para a criança tenha uma atitude diferente do comum virar de páginas que normalmente caracteriza a interação com o livro, e explore esse objeto de outra maneira.

O livro, aparentemente simples, com poucas imagens, como dito antes: todo o pacote faz parte da produção de sentido, mas nesse caso, a voz narrativa é um elemento de interação que se destaca. Tendo como principal objetivo guiar os leitores na maneira de como conduzir a leitura do livro, por exemplo, na página 12 quando o narrador fala sobre como o Coelho estava vestido na página anterior que apresenta a sua imagem, fazendo com que a curiosidade seja provocada, fazendo o leitor querer voltar a página (FIGURA 2) e verificar se as informações descritas são condizentes.

A voz narrativa também incita a curiosidade nas crianças para que elas consigam manter a sua atenção na continuidade da história e na relação com o livro. Temos como exemplo disso, novamente na página 12, na qual lemos: "Mas chegará atrasado aonde? Bem, veja só, ele tinha de ir se encontrar com a Duquesa. (Você logo verá um retrato da Duquesa sentada na sua cozinha.)" (CARROLL, [1890] 2013).

Compreendemos no livro Alice no jardim de infância (CARROLL, [1890] 2013) que a voz do narrador da história possui posição de extrema relevância. Especificamente antecipação e hipótese. Demonstrando esse fator com o mesmo exemplo 
utilizado anteriormente, "(Você logo verá um retrato da Duquesa sentada na sua cozinha.)" (CARROLL, [1890] 2013), a criança, além de se manter curiosa e atenta, criará uma imagem mental, uma hipótese de como ela é, utilizando todos os seus conhecimentos prévios. Como, por exemplo, se já viu imagens de duquesas, princesas ou rainhas em outros livros, pode associar as imagens e criar uma para representar a personagem. A antecipação feita será logo comparada com a figura original e sua hipótese virá a ser atestada ou contrariada $(\mathrm{KOCH}, 2006$, p.13). O narrador promove o exercício da predição baseado nos conhecimentos prévios do leitor, provoca-o a confirmar ou refazer suas hipóteses, retomar informações, aguardar por outras novas em um movimento essencial de uso de estratégias de leitura que auxiliam no desenvolvimento da compreensão leitora.

Para além daquilo que Nikolajeva e Scott (2011, p.156) apontam como os quatro traços mais evidentes da presença do narrador no texto - "a descrição do cenário, a descrição do personagem, o resumo dos acontecimentos e os comentários sobre os acontecimentos ou as ações dos personagens"- , essa adaptação de Lewis Carroll inova ao pensar na voz narrativa como mediadora para as crianças ainda não leitoras do texto verbal. Carroll utiliza o recurso da voz narrativa, dirigindo-se ao leitor e também auxiliando o mediador a manter a atenção da criança na leitura. O fim do capítulo não significa o final da história, o autor encurta a narrativa em extensão, mas não deixa de contar todos o fatos que a constituem, e o narrador assume como missão manter essa criança atenta à história apresentada ao longo das páginas: "da próxima vez que você vir o Coelho Branco, tente imaginar que você também vai ter um sonho curioso, tal como o dessa garotinha, Alice." (p. 13).

\section{Considerações finais}

A leitura na escola, principalmente no contexto da Educação Infantil, permanece com o caráter coletivo e solidário que caracterizava o ato de ler antes da prensa de Gutenberg e até mesmo no princípio do surgimento dessa invenção. Saber explorar o livro como objeto de interação é parte da mediação da leitura que é importante para iniciar o processo de formação leitora, envolvendo a criança em práticas de leitura mesmo antes da alfabetização formal.

$\mathrm{Na}$ obra Alice no jardim de infância (CARROLL, [1890] 2013), a voz narrativa associada ao objeto livro oferece ao leitor mediador da criança ainda não leitora da palavra recursos para explorar o livro. O narrador contagia (LANDOWSKI, 2014) o leitor a interagir com o livro. Segundo Belo (2008, p.35): "Além do texto, o leitor atribui significado aos elementos que também fazem parte do livro e que vão influenciar a sua percepção [daquilo que lê] ". O virar de páginas, o recuperar informações já lidas e vistas ao longo das páginas, o movimento de ir e vir, são ações que fazem parte da relação que se estabelece com o livro e importantes na produção de sentido durante a leitura. O narrador no capítulo analisado e ao longo da obra desenvolve estratégias de mediação para modificar o agir do leitor, diante do livro para fazer muito mais do que somente ouvir a história contada, admirar as imagens, mas principalmente, produzir sentido a partir da interação, seja respondendo aos questionamentos que 0 narrador o faz, movimentando o livro de modo diferente (mexer o livro para cima e para baixo fazendo coelho "tremer" de medo, por exemplo) para produzir sentido ou se sentindo curioso para saber o que virá a seguir na história.

Além disso, o modo com que as informações são apresentadas a cada página promovem um olhar e considerar essas informações que possibilitam ao leitor organizar, qualificar, selecionar o que vê e como lê. Essa interação entre as partes, que para Lins (2003) revelam um ritmo do livro, também são exploradas no livro analisado e podem ser importantes ferramentas para uma mediação não apenas da leitura, mas principalmente da relação do leitor com o livro.

A história Alice no jardim de infância foi adaptada pelo autor a partir de seu livro Alice no país das maravilhas, em 1890, pensando no público da 
Educação Infantil. A história clássica adaptada ao público não leitor da palavra revela uma linguagem simples e ainda assim intrigante pela maneira com que o narrador se comunica diretamente com o leitor, dispensando outras ferramentas atrativas exploradas contemporaneamente em livros voltados para o leitor de 0 a 5 anos (como pop-ups e texturas, por exemplo). O leitor é contagiado a interagir com o livro pela voz narrativa que procura manter as crianças escutando a leitura e vendo as imagens, ansiosas pela próxima página. Essa voz narrativa associada à constituição do livro, objeto cujo manuseio traz implícito algumas ações (abrir o livro, virar suas páginas para avançar na leitura, etc.), são auxiliares importantes na mediação tanto da leitura quanto da interação com livro.

Como Lins (2003, p.36) disse, "o mundo muda, a moda muda, tudo muda. A criança de hoje pensa, lê e vê o mundo de uma forma diferente". As gerações estão em constante mudança e, por isso, é de extrema importância que os educadores se mantenham na posição também de aprendizes, sempre a procura de novos saberes que possam auxiliar na mediação de ensino-aprendizagem. Além disso, é necessário se manter a par das novas criações literárias. Quando dizemos isso não nos referimos somente às novas tecnologias, mas sim a livros como 0 analisado, que permitirão 0 desenvolvimento de um vínculo com o livro que até hoje, apesar de todas as mudanças culturais que ocorreram, não perdeu sua forma original e seu apelo.

\section{Referências}

BELO, André. História \& Livro e Leitura. Belo Horizonte: Autêntica, 2008.

CARROLL, Lewis. Alice no jardim de infância. trad. Sérgio Medeiros. São Paulo: lluminuras, 2013.
CHARTIER, Roger. A aventura do livro: do leitor ao navegador. São Paulo: Editora UNESP, 1998.

DALVI, Maria Amélia; QUADROS, Marta Campos de; SILVA, Kenia Adriana de Aquino Modesto. A leitura em voz alta na educação infantil: o que e como ler. In: GIROTTO, Cynthia Graziella Guizelim Simões; SOUZA, Renata Junqueira de. (Orgs.). Literatura e educação infantil: para ler, contar e encantar. Campinas, SP: Mercado das Letras, 2016, p. 29-64.

GOMES, Cristiano Mauro Assis. Experiência de aprendizagem mediada. In: .Feuerstein e a construção mediada do conhecimento. Porto Alegre: Artmed, 2002, p. 71-105.

HUNT, Peter. Crítica, teoria e literatura infantil. trad. Cid Knipel. São Paulo: Cosac Naify, 2010.

$\mathrm{KOCH}$, Ingedore Villaça. Ler e compreender: os sentidos do texto. 2.ed. São Paulo, Contexto, 2006.

LANDOWSKI, Eric. Interações arriscadas. trad. Luiza Helena Oliveira da Silva. São Paulo: Estação das Letras e Cores: Centro de Pesquisas Sociossemióticas, 2014a.

Sociossemiótica: uma teoria geral do sentido. Galaxia. São Paulo, Online, n.27, p.10-20, jun. 2014b

LINS, Guto. Livro Infantil?: projeto gráfico, metodologia, subjetividade. São Paulo: Edições Rosari, 2003.

MATTE, Ana Cristina Fricke; LARA, Glaucia Muniz Proença. Um panorama da semiótica greimasiana. Alfa. São Paulo, n. 53, p. 339-350, 2009.

NIKOLAJEVA, Maria; SCOTT, Carole. Livro ilustrado: palavras e imagens. Tradução de Cid Knipel. São Paulo: Cosac Naify, 2011.

NUNES, Marília Forgearini. Como lê uma criança que ainda não foi alfabetizada?. Textura, Canoas, n.16, p.100-111, jul/dez 2007.

REIS, Carlos; LOPES, Ana Cristina M. Lopes. Dicionário de narratologia. 2.ed. Coimbra, Portugal: Almedina, 1990.

VIGOSTKI, L. S. A formação social da mente. 6.ed. São Paulo: Martins Fontes, 1998.

ZILBERMAN, Regina. Fim do livro, fim dos leitores? São Paulo: Editora Senac, 2001.

\section{COMO CITAR ESSE ARTIGO}

NUNES, Marilia Forgearini; MARTINI, Júlia Soares. O livro e a sua mediação na infância. Signo, Santa Cruz do Sul, v. 43, n. 78 , p. 24-31, nov. 2018. ISSN 1982-2014. Disponível em: <https://online.unisc.br/seer/index.php/signo/article/view/12030>. Acesso em: https://doi.org/10.17058/signo.v43i78.12030. 